\title{
PENAMPUNGAN AIR BERSIH PADA MUSIM KEMARAU DENGAN PEMANFAATAN EMBUNG GEOMEMBRANE (Studi Kasus: Desa Tanggung Prigel, Glagah, Lamongan)
}

\author{
Hammam Rofiqi Agustapraja ${ }^{1, *)}$, Mukhammad Alifuddin ${ }^{1)}$ \\ ${ }^{1}$ Program Studi Teknik Sipil Fakultas Teknik Universitas Islam Lamongan \\ Jl. Veteran 53A, Jetis, Lamongan \\ ${ }^{*}$ Email: hammamrofiqi@unisla.ac.id
}

\begin{abstract}
Water is a major and important resource in the process of life in the world because of every living creature whether human, animal, and plant needs water. The technology of artificial geomembrane reservoir or water tank is the small reservoir in the village land (TKD) which is built to collect the water in the rainy season by using waterproof material as the layer by utilizing the rainwater through the river around which is then used as an alternative source of clean water (water supply) in the dry season. As for the calculation methods used for this research include: analysis of rainfall area using algebra average method (arithmetic mean), the calculation of rainfall plan can be done by using disperse measurement, with the statistical parameter of the calculation result of $S d=23.884 C s=1.933 C k=4.031$ $C v=0.233$. The distribution analysis is done using the Gumbel 1 method for 10 years plan amounted to $146.601 \mathrm{~mm} /$ day. Rainfall intensity analysis is done by using the Mononobe method for 10 years rainfall intensity plan amounted to 6.108 $\mathrm{mm} /$ hour. For the next 10 years, population projection is done using a calculation of the Arithmetic method of 2.795 populations. The conclusion of this research indicates that the clean water need in the dry season at Tanggung Prigel Village, Glagah District in 2026 is approximately $0.001941 \mathrm{~m} 3 / \mathrm{sec}$. While the plan for reservoir debit of $0.003254 \mathrm{~m} 3 / \mathrm{sec}$ so it is considered sufficient to fulfill the clean water need in the Tanggung Prigel Village, Glagah District.
\end{abstract}

Kata kunci : Reservoir, Geomembrane, Clean Water, Debit

\section{PENDAHULUAN}

Air merupakan sumber daya dan faktor determinan yang sangat penting dalam kehidupan karena tidak ada satu pun makhluk hidup baik tanaman, ikan dan ternak yang tidak memerlukan air. Meskipun perannya sangat strategis, namun pengelolaan air masih jauh dari yang diharapkan, sehingga air yang semestinya merupakan kebutuhan pokok manusia berubah menjadi penyebab bencana bagi manusia. Indikatornya, di musim kemarau, kekurangan air bersih ladang dan sawah sering kali kekeringan dan sebaliknya di musim penghujan, ladang dan sawah banyak yang terendam air.

Secara kuantitas, permasalahan air bagi masyarakat terutama di musim kemarau adalah persoalan ketidaksesuaian distribusi air antara kebutuhan dan pasokan menurut waktu (temporal) dan tempat (spatial). Persoalan menjadi semakin kompleks, rumit dan sulit diprediksi karena 
pasokan air tergantung dari sebaran curah hujan di sepanjang tahun, yang sebarannya tidak merata walau di musim hujan sekalipun. Oleh karena itu, diperlukan teknologi tepat guna, murah dan efektif untuk mengatur ketersediaan air agar dapat memenuhi kebutuhan air (water demand) yang semakin sulit dilakukan dengan caracara alamiah (natural manner). Teknologi embung geomembrane atau tandon air merupakan salah satu pilihan yang menjanjikan karena teknologinya sederhana, biayanya relatif murah di bandingkan embung permanen menggunakan beton dan mudah di terapkan.

Embung geomembrane buatan atau tandon air merupakan waduk berukuran mikro di lahan yang berasal dari tanah kas desa (TKD) yang dibangun untuk menampung kelebihan air pada musim hujan dengan menggunakan material kedap air sebagai lapisannya dengan cara memanfaatkan tangkapan air hujan (sungai) di sekitarnya. Di lahan tanah kas desa di bangun embung geomembrane yang berfungsi sebagai tempat penampungan air drainase saat kelebihan air di musim hujan dan sebagai sumber air baku ( bersih ) pada musim kemarau.

Pada Desa Tanggung Prigel Kecamatan Glagah Lamongan tersebut ketersediaan air bersih sangat kurang di musim kemarau, karena saat musim penghujan biasanya warga memanfaatkan air yang berasal dari air sungai untuk keperluan sehari-hari. Air tersebut di gunakan untuk semua kegiatan seperti air untuk mencuci, mandi, wudhu, menyiram tanaman, minum ternak dan sumber air darurat untuk antisipasi kebakaran. Untuk kegunaan itu maka dapat di gunakan penampung air (embung geomembrane) sebagai alternative untuk cadangan air baku di waktu musim kemarau. Karena kendala yang dihadapi sumber air bawah tanah (sumur gali) airnya cenderung asin, dan untuk memperoleh air tawar dan bersih warga harus membeli. Sedangkan konsumsi air bersih sangat dibutuhkan sehingga peneliti memilih tempat tersebut untuk dijadikan tempat penelitian.

Tujuan penelitian ini untuk mengetahui kondisi ketersediaan air setelah adanya embung geomembrane dan untuk mengetahui kondisi ketersediaan air baku serta untuk mengetahui teknik dan tata cara proses pembuatan embung geomembrane di desa Tanggung Prigel kecamatan Glagah-Lamongan.

\section{METODE PENELITIAN}

Dalam melaksanakan penelitian ini, secara garis besar tahapan yang dilakukan adalah sebagai berikut:

1. Perumusan Masalah

Dalam bagian ini dipaparkan permasalahan yang akan dibahas dalam penulisan skripsi ini.

2. Studi Literatur Dan Pengumpulan Data

Dalam bagian ini dilakukan studi literatur dan pencarian data-data dari berbagai sumber yang berkaitan dengan penulisan skripsi ini, seperti 1) Metode panen air hujan dengan sistem penyimpanan di embung 
geomembrane, 2) Data Topografi, 3) Data curah hujan wilayah studi, dan 4) Data Jumlah Penduduk

3. Metode Panen Air Hujan

Dalam bagian ini dilakukan deskripsi mengenai sistem panen air hujan yang dapat digunakan untuk mengumpulkan dan menyimpan volume limpasan air hujan, sungai tersebut untuk kemudian digunakan kembali.

4. Perhitungan Hidrologi, Volume Limpasan, dan Luas Permukaan Embung

Dalam bagian ini dilakukan pengolahan data curah hujan untuk memperoleh volume limpasan air hujan yang jatuh di permukaan embung dan sekitar aliran sungai di Desa Tanggung Prigel. Dengan menggunakan data curah hujan dan luasan permukaan embung didapat volume limpasan air hujan yang jatuh di embung.

5. Perhitungan Volume Limpasan Tertampung

Pada bagian ini dilakukan pengolahan data untuk memperoleh volume limpasan air hujan yang jatuh di embung sebagai daerah tangkapan (catchment area) untuk mengetahui seberapa banyak dari volume limpasan air hujan yang akan ditampung pada sistem instalasi panen air hujan yang akan digunakan.

6. Efisiensi Metode Panen Hujan dengan menggunakan embung geomembrane.

Pada bagian ini dilakukan analisa pengolahan data untuk menentukan efisiensi dari sistem instalasi panen air hujan yang dipilih dan apabila tingkat efisisensi yang dicapai masih belum memenuhi tingkat efisiensi yang diinginkan maka dilakukan pemilihan metode lain dari panen air hujan.

7. Analisis

Dari hasil penelitian ini selanjutnya jika efisiensi yang dicapai tidak sesuai untuk diterapkan maka bagian ini akan memberikan analisa mengenai penyebab rendahnya nilai efisiensi dan langkah yang dapat ditempuh untuk memperbaiki nilai efisiensi tersebut.

8. Kesimpulan Dan Rekomendasi Pada bagian ini disimpulkan dan diberikan rekomendasi dari semua pokok permasalahan yang telah dianalisa dalam penelitian ini, sebagai pedoman penelitian di masa yang akan datang yang berkaitan dengan pokok permasalahan ini.

HASIL DAN PEMBAHASAN

Menentukan Volume

Kolam Penampung

Untuk menentukan volume kolam penampung (embung geomembrane) maka perlu diketahui volume air yang terpanen di embung dan volume air yang dibutuhkan. Jadi untuk menentukan volume kolam penampung, dapat diketahui dengan rumus sebagai berikut :

Diketahui: panjang embung: 50,00 m, lebar embung : 50,00 m, tinggi / kedalaman embung : 3,00 m. Maka untuk menghitung volume ini digunakan persamaan menggunakan rumus ( 2.1 ) sebagai berikut : $\mathrm{V}=\mathrm{P} \times \mathrm{L} \times \mathrm{T}$ 
Dimana :

$\mathrm{V}=\operatorname{Volume}\left(\mathrm{m}^{3}\right)$

$\mathrm{P}=$ PanjangEmbung $(\mathrm{m})$

$\mathrm{L}=\operatorname{LebarEmbung}(\mathrm{m})$

$\mathrm{T}=$ Tinggi/kedalaman

Embung ( m )

Maka :

$\mathrm{V}=50,00 \times 50,00 \times 3,00=$ $7500 \mathrm{~m}^{3}$

$7500 \mathrm{~m}^{3} \times 1000=7.500 .000$

Liter

Jadi volume embung geomembrane dapat menampung air : 7.500.000 Liter.

\section{Jumlah penduduk 10 \\ Tahun mendatang (proyeksi)}

Untuk memperkirakan jumlah pendududuk 10 tahun mendatang dapat kita perkirakan jumlahnya (proyeksikan ) dengan bantuan rumus. Perkiraan jumlah penduduk beberapa tahun mendatang itu sangat berguna dalam perencanaan pembangunan embung, misalnya dalam hal menghitung kebutuhan air bersih (baku) di Desa Tanggung Prigel Kecamatan Glagah dalam 10 tahun mendatang. Berdasarkan pada tabel 4.3 dapat diketahui tingkat pertumbuhan penduduk Desa Tanggung Prigel dalam 10 tahun terakhir, dan untuk jumlah penduduk terakhir berdasarkan data yang di dapat tahun 2015 jumlah penduduk 2550 jiwa, dengan angka pertumbuhan penduduk rata-rata 24,5 jiwa tiap tahunnya. Maka untuk memperkirakan jumlah penduduk untuk 10 tahun kedepan yaitu tahun rencana 2026 dapat dihitung dengan menggunakan metode Arithmatik persamaan ( 2.2 ) sebagai berikut :

$\mathrm{P}_{\mathrm{n}}=\mathrm{P}_{\mathrm{o}}+\mathrm{r}(\mathrm{n})$ dan $\mathrm{r}=\frac{P o+P t}{t}$

Dimana :

$\mathrm{P}_{\mathrm{n}}=$ Jumlah penduduk pada tahun $\mathrm{n}$ (ditanyakan)

$\mathrm{P}_{\mathrm{o}}=$ Jumlah penduduk awal tahun proyeksi

$\mathrm{n}$ = Periode waktu yang di tinjau

$r \quad=$ Tingkat pertumbuhan penduduk tiap tahun

$\mathrm{t}=$ Banyak tahun sebelum tahun analisis

$\mathrm{Pt}=$ Jumlah penduduk pada tahun ke akhir/ke -t

Berdasarkan dari data yang di dapat pada tabel (4.4) maka :

Po $=$ Jumlah penduduk pada tahun 2016

$=2550$ jiwa

$\mathrm{Pt}=$ Jumlah penduduk pada awal tahun 2007

$=2329$ jiwa

$\mathrm{t}=2016-2007$

$\mathrm{r}=\frac{(2550-2329)}{(2016-2007)}$

$\mathrm{r}=\frac{221}{9}$

$\mathrm{r}=24,555$

maka di dapat persamaan arithmatik :

$\mathrm{Pn}=\mathrm{Po}+\mathrm{r} \mathrm{n}$

$P n=2550+24,555 n$ 
Tabel 1. Perhitungan Proyeksi Penduduk Tahun 2016-2026

Berdasarkan Metode Arithmatik

\begin{tabular}{cccc}
\hline No & Tahun & N & $\begin{array}{c}\text { Metode Arithmatik Pn= 2550+24,555.N } \\
\text { (jiwa) }\end{array}$ \\
\hline 1 & 2016 & 0 & 2550 \\
2 & 2017 & 1 & 2574 \\
3 & 2018 & 2 & 2599 \\
4 & 2019 & 3 & 2624 \\
5 & 2010 & 4 & 2648 \\
6 & 2021 & 5 & 2673 \\
7 & 2022 & 6 & 2697 \\
8 & 2023 & 7 & 2722 \\
9 & 2024 & 8 & 2746 \\
10 & 2025 & 9 & 2771 \\
11 & 2026 & 10 & 2795 \\
\hline
\end{tabular}

Sumber : Olah Data

Dari hasil perhitungan tersebut dapat di proyeksikan jumlah penduduk Desa Tanggung Prigel untuk 10 Tahun kedepan pada Tahun 2026 berjumlah : 2.795 jiwa.

\section{Menghitung kebutuhan air bersih beberapa tahun mendatang}

Dasar perencanaan dari perhitungan air bersih (baku) dari suatu daerah adalah banyaknya populasi, kegiatan serta kebiasaan yang dilakukan sehari-hari populasi ditempat tersebut. Berdasarkan kriteria pada tabel (2.1), dengan jumlah warga desa dukuh tunggal 2.795 jiwa maka dapat dikatakan kota kecil dan diambil ratarata kebutuhan air bersih adalah 100 liter/orang/harinya. Yang umumnya kebutuhan air bersih untuk mandi, mencuci, wudhu, dan lain-lain.

Maka berdasarkan dari persamaan rumus (2.3) diperoleh :

1. Kebutuhan air bersih $\left(\mathrm{Q}_{\mathrm{md}}\right)$

$\mathrm{Q}_{\mathrm{md}}=\mathrm{P}_{\mathrm{n}} \mathrm{xq}$

Dimana :

$\mathrm{Q}_{\mathrm{md}}=$ Kebutuhan air bersih
$\mathrm{P}_{\mathrm{n}}=$ Jumlah penduduk tahun $\mathrm{n}$

$\mathrm{Q}=$ Kebutuhan air per orang/hari

$\mathrm{Q}_{\mathrm{md}}=\mathrm{P}_{\mathrm{n}} \times \mathrm{q}$ $=2.795 \times 60$ liter/orang/hari $=167.700$ liter $/$ hari $=1,9409$ liter $/ \mathrm{deti \textrm {k }}$ $=0,001941 \mathrm{~m}^{3} /$ detik

Dari perhitungan di atas maka dapat diketahui untuk kebutuhan air bersih sebesar : 0,001941 $\mathrm{m}^{3} /$ detik.

\section{Analisis Curah Hujan Rencana}

Untuk menentukan curah hujan rencana berdasarkan data hujan di stasiun Blawi, stasiun Karangbinangun dan stasiun Kuro di dapatkan curah hujan maksimum pada tiap-tiap stasiun. Maka dapat digunakan metode rata-rata aljabar (Arithmatic mean) sebagai berikut :

Rumus :

$\bar{R}=1 / \mathrm{n}(\mathrm{R} 1+\mathrm{R} 2+\ldots \ldots \ldots+\mathrm{Rn})$

$\bar{R}=$ Curah hujan maksimum rata-rata DAS (mm)

$\mathrm{N}=$ Jumlah stasiun pengamatan 
$\mathrm{R} 1=$ Curah hujan pada stasiun $\mathrm{Rn}=$ Curah hujan pada stasiun pengamatan satu $(\mathrm{mm})$

R2 = Curah hujan pada stasiun Hasil perhitungan yang akan di sajikan pengamatan dua $(\mathrm{mm})$ pada tabel di bawah ini.

Tabel 2. Data Curah Hujan Harian Maksimum Metode Rata-rata aljabar

\begin{tabular}{ccccc}
\hline Tahun & $\begin{array}{c}\text { Stasiun Blawi } \\
(\mathrm{mm})\end{array}$ & $\begin{array}{c}\text { Stasiun } \\
\text { Karangbinangun }(\mathrm{mm})\end{array}$ & $\begin{array}{c}\text { Stasiun Kuro } \\
(\mathrm{mm})\end{array}$ & $\begin{array}{c}\mathrm{CH} \\
\text { rata-rata max }\end{array}$ \\
\hline 2007 & 65 & 80 & 90 & 78,3 \\
2008 & 200 & 164 & 122 & 162 \\
2009 & 55 & 124 & 97 & 92 \\
2010 & 81 & 85 & 121 & 96 \\
2011 & 96 & 105 & 110 & 104 \\
2012 & 113 & 86 & 128 & 109 \\
2013 & 75 & 72 & 104 & 84 \\
2014 & 119 & 123 & 109 & 117 \\
2015 & 75 & 90 & 106 & 90,3 \\
2016 & 110 & 78 & 88 & 92 \\
\hline
\end{tabular}

Sumber : perhitungan metode aljabar (aritmatic mean)

Perhitungan Curah Hujan Rencana

\section{Melalui Pengukuran Dispersi}

Untuk mengetahui Besarya dispersi dapat dilakukan pengukuran dispersi yaitu melalui perhitungan parameter statistic untuk $(\mathrm{Xi}-\mathrm{X}),(\mathrm{Xi}-\mathrm{X})^{2},(\mathrm{Xi}$ $\mathrm{X})^{3},(\mathrm{Xi}-\mathrm{X})^{4}$ terlebih dahulu.
Dimana :

$\mathrm{Xi}=$ Besarya curah hujan daerah $(\mathrm{mm})$ $\mathrm{X}=$ Rata-rata curah hujan maksimum daerah ( $\mathrm{mm}$ )

Untuk menentukan pengukuran dispersi yang disajikan dalam tabel di bawah ini :

Tabel 3. Perhitungan Dispersi

\begin{tabular}{|c|c|c|c|c|c|c|c|}
\hline No & Tahun & $\operatorname{Rh}\left(X_{1}\right)$ & $\begin{array}{c}\text { Rh Rata-rata } \\
(\mathrm{X})\end{array}$ & $\left(\mathbf{X}_{1}-\mathbf{X}\right)$ & $\left(\mathbf{X}_{1}-\mathbf{X}\right)^{2}$ & $\left(\mathbf{X}_{1}-\mathbf{X}\right)^{3}$ & $\left(X_{1}-X\right)^{4}$ \\
\hline 1 & 2007 & 78,3 & 102,46 & $-24,16$ & 583,7 & $-14102,3$ & 340712,2 \\
\hline 2 & 2008 & 162 & 102,46 & 59,54 & 3545 & 211069,9 & 12567107,2 \\
\hline 3 & 2009 & 92 & 102,46 & $-10,46$ & 109,4 & $-1144,44$ & 11970,8 \\
\hline 4 & 2010 & 96 & 102,46 & $-6,46$ & 41,73 & $-269,58$ & 1741,48 \\
\hline 5 & 2011 & 104 & 102,46 & 1,54 & 2,37 & 3,65 & 5,621 \\
\hline 6 & 2012 & 109 & 102,46 & 6,54 & 42,77 & 279,72 & 1829,4 \\
\hline 7 & 2013 & 84 & 102,46 & $-18,46$ & 340,77 & $-6290,64$ & 116125,2 \\
\hline 8 & 2014 & 117 & 102,46 & 14,54 & 211,41 & 3073,92 & 44694,8 \\
\hline 9 & 2015 & 90,3 & 102,46 & $-12,16$ & 147,86 & $-1798,04$ & 21864,2 \\
\hline 10 & 2016 & 92 & 102,46 & $-10,46$ & 109,41 & $-1144,44$ & 11970,8 \\
\hline \multicolumn{2}{|c|}{ Jumlah } & 1024,6 & & 0,0 & 5134,43 & 189677,8 & 13118021,9 \\
\hline
\end{tabular}

Sumber : Olah Data Primer 
Adapun macam pengukuran dispersi antara lain :

\section{Deviasi standar (Sd)}

Untuk mengetahui nilai Sd digunakan persamaan (2.5) sebagai berikut :

$\mathrm{Sd}=\frac{\sqrt{\sum(x i-\mathrm{x})^{2}}}{n-1}$

Dimana :

$\mathrm{Sd}=$ Deviasi standar

$\mathrm{X}=$ Curah hujan rata-rata ( $\mathrm{mm} / \mathrm{hari})$

$\mathrm{X}_{\mathrm{i}}=$ Curah hujan minimum (mm/hari)

$\mathrm{n}$ = Lamanya pengamatan

Maka :

$\mathrm{Sd}=\frac{\sqrt{\sum(x i-\mathrm{x})^{2}}}{n-1}$

$$
=\frac{\sqrt{5134,43}}{10-1}
$$

$\mathrm{Sd}=23,884$

\section{Koefisien skewness (Cs)}

Untuk kemencengan (skewness) digunakan persamaan (2.6) sebagai berikut :

$\mathrm{Cs}=\frac{\mathrm{n} \sum_{\mathrm{i}=1}^{\mathrm{n}}\{(\mathrm{xi})-\mathrm{x}\}^{3}}{(\mathrm{n}-1)(\mathrm{n}-2) \mathrm{Sd}^{3}}$

Dimana :

Cs $=$ Koefisien kemencengan

$\mathrm{X}_{\mathrm{i}}=$ Nilai variat

$\mathrm{X}=$ Nilai rata-rata

$\mathrm{n}=$ Jumlah data

Maka :

$$
\begin{aligned}
\mathrm{Cs} & =\frac{\mathrm{n} \sum_{\mathrm{i}=1}^{\mathrm{n}}\{(\mathrm{xi})-\mathrm{x}\}^{3}}{(\mathrm{n}-1)(\mathrm{n}-2) \mathrm{Sd}^{3}} \\
& =\frac{10.189677,82}{(10-1)(10-2) \cdot 23,884^{3}}
\end{aligned}
$$

$\mathrm{Cs}=1,933$

\section{Koefisien kurtosis (Ck)}

Perhitungan kurtosis menggunakan persamaan (2.7) sebagai berikut :

$\mathrm{Ck}=\frac{\mathrm{n} \sum_{\mathrm{i}=1}^{\mathrm{n}}\{(\mathrm{xi})-\mathrm{x}\}^{4}}{\mathrm{Sd}^{4}}$

Dimana :

$\mathrm{Ck}=$ Koefisien kurtosis

$\mathrm{X}_{\mathrm{i}}=$ Nilai variat
$\mathrm{X}=$ Nilai rata-rata

$\mathrm{n}=$ Jumlah data

$\mathrm{Sd}=$ standar deviasi

Maka :

$\mathrm{Ck}=\frac{\mathrm{n} \sum_{\mathrm{i}=1}^{\mathrm{n}}\{(\mathrm{xi})-\mathrm{x}\}^{4}}{\mathrm{Sd}^{4}}$

$$
=\frac{\frac{1}{10} 13118021,94}{23,884^{4}}
$$$$
=\frac{1311802,194}{325408,018}
$$

$\mathrm{Ck}=4,031$

\section{Koefisien variasi $(\mathrm{Cv})$}

Untuk menghitung koefisien variasi digunakan persamaan (2.8) sebagai berikut :

$\mathrm{Cv}=\frac{S d}{X}$

Dimana :

$\mathrm{Cv}=$ Koefisien variasi

$\mathrm{Sd}=$ Standar deviasi

$\mathrm{X}=$ Nilai rata-rata

Maka :

$$
\begin{aligned}
\mathrm{Cv} & =\frac{s d}{X} \\
& =\frac{23,884}{102,46} \\
\mathrm{Cv} & =0,233
\end{aligned}
$$

\section{Analisis Sebaran Metode Distribusi} Gumbel 1

Berdasarkan pada tabel (2.1) kriteria pemilihan jenis distribusi teoritis, dengan hasil perhitungan $\mathrm{Cs}=1,933$ dan $\mathrm{Ck}=4,031$ maka metode distribusi gumbel di anggap sudah mendekati persyaratan yang telah ditentukan. Untuk menentukan curah hujan rancangan dipakai analisa gumbel. Untuk perhitungan dipakai persamaaan (2.9) :

$$
\mathrm{X}_{\mathrm{T}}=\mathrm{X}+\frac{s}{S n}\left(\mathrm{Y}_{\mathrm{t}}-\mathrm{Y}_{\mathrm{n}}\right)
$$

Dimana : 
$\mathrm{X}_{\mathrm{T}}=$ Curah hujan rencana dalam periode ulang $\mathrm{T}$ tahun ( $\mathrm{mm} / \mathrm{hari})$

$\mathrm{X}=$ Curah hujan rata-rata hasil pengamatan

$\mathrm{Y}_{\mathrm{t}}=$ Reduced variabel, parameter gumbel untuk periode $\mathrm{T}$ tahun (tabel 2.3)

$\mathrm{Y}_{\mathrm{n}}=$ Reduced mean, merupakan fungsi dari banyaknya data (n) (tabel 2.1)
$\mathrm{S}=$ Standar deviasi

Sn = Reduced standar deviasi, merupakan fungsi dari banyaknya data (n) (tabel 2.2)

Maka untuk mengetahui perhitungan distribusi sebaran metode gumbel untuk tahun rencana 10 tahun disajikan pada tabel di bawah ini :

Tabel 4. Distribusi Sebaran Metode Gumbel

\begin{tabular}{cccccccc}
\hline No & Periode & $\mathrm{X}$ & $\mathrm{Sd}$ & $\mathrm{Sn}$ & $\mathrm{Yn}$ & $\mathrm{Yt}$ & $\mathrm{Xt}$ \\
\hline 1 & 2 & 102,46 & 23,88 & 0,94 & 0,49 & 0,36 & 11,96 \\
2 & 5 & 102,46 & 23,88 & 0,94 & 0,49 & 1,49 & 128,09 \\
3 & 10 & 102,46 & 23,88 & 0,94 & 0,49 & 2,25 & 204,96 \\
\hline
\end{tabular}

Sumber : Olah Data Primer

\section{Intesitas Curah Hujan}

Perhitungan intensitas curah hujan menggunakan metode Dr. Mononobe dengan persamaan (2.10) sebagai berikut :

$\mathrm{I}=\frac{R 24}{24}\left(\frac{24}{t}\right)^{2 / 3}$

Dimana :
I = intensitas hujan ( $\mathrm{mm} / \mathrm{jam})$

R24 = curah hujan maksimum harian dalam 24 jam (mm/jam)

$\mathrm{t} \quad=$ lama hujan

maka untuk perhitungan disajikan dalam tabel dibawah ini:

Tabel 5. Intesitas Curah Hujan Dengan Mononobe

\begin{tabular}{cccc}
\hline T (jam) & \multicolumn{3}{c}{ R24 } \\
\cline { 2 - 4 } & R2 $(99,222)$ & R5 $(127,729)$ & R10 $(146,601)$ \\
\hline 1 & 34,398 & 44,281 & 50,823 \\
2 & 21,669 & 27,895 & 32,016 \\
3 & 16,537 & 21,288 & 24,433 \\
4 & 13,650 & 17,572 & 20,169 \\
5 & 11,764 & 15,143 & 17,381 \\
6 & 10,417 & 13,410 & 15,392 \\
7 & 9,400 & 12,100 & 13,888 \\
8 & 8,599 & 11,070 & 12,705 \\
9 & 7,950 & 10,234 & 11,746 \\
10 & 7,410 & 9,540 & 10,949 \\
11 & 6,954 & 8,952 & 10,275 \\
12 & 6,562 & 8,448 & 9,696 \\
13 & 6,221 & 8,009 & 9,192 \\
14 & 5,921 & 7,623 & 8,749
\end{tabular}




\begin{tabular}{llll}
15 & 5,655 & 7,280 & 8,356 \\
16 & 5,417 & 6,973 & 8,004 \\
17 & 5,202 & 6,697 & 7,687 \\
18 & 5,008 & 6,447 & 7,399 \\
19 & 4,830 & 6,218 & 7,137 \\
20 & 4,668 & 6,009 & 6,897 \\
21 & 4,519 & 5,817 & 6,677 \\
22 & 4,381 & 5,639 & 6,473 \\
23 & 4,253 & 5,475 & 6,284 \\
24 & 4,134 & 5,322 & 6,108 \\
\hline
\end{tabular}

Sumber : Olah Data Primer

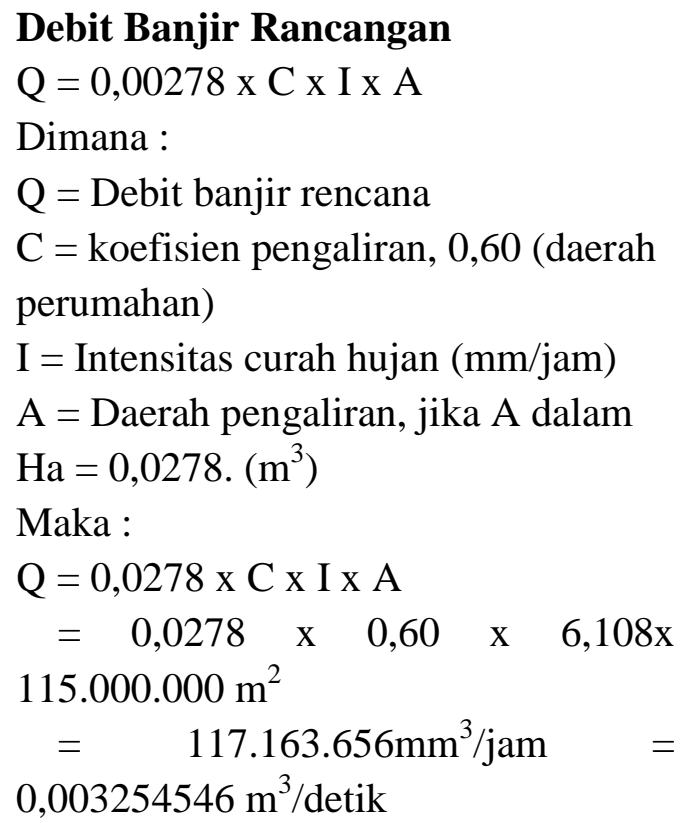

Dari perhitungan debit banjir rancangan yaitu sebesar 0,00325 $\mathrm{m}^{3} /$ detik

\section{Kontruksi Embung Geomembrane}

Untuk kontruksi pemanenan air hujan dengan embung geomembrane bisa di buat lebih cepat dan dengan biaya lebih ekonomis dalam pembuatanya, bila di bandingkan dengan embung permanen yang menggunakan beton sebagai lapisannya. Yang pada dasarnya geomembrane dan beton sama-sama berfungsi sama yaitu mengurangi resapan pada embung tersebut. Adapun proses-proses kontruksi dalam pembuatan embung geomembrane adalah sebagai berikut :

1. Survey lapangan untuk menentukan letak lokasi pembuatan embung geomembrane yang harus memenuhi beberapa kriteria antara lain :

a. Adanya tanah (tempat) yang resmi dan tidak dalam sengketa, misalnya adanya tanah kas desa ( TKD )

b. Akses keluar masuk alat berat dan buangan tanah harus terpenuhi

c. Ada tangkapan air hujan (catchmen area) yang bisa di arahkan ke embung geomembrane tercukupi

d. Lokasi tidak jauh dari pemukiman

2. Mendesain gambar sederhana embung geomembrane

3. Mempersiapkan material dan alat berat alat

4. Pengalian tanah (normalisasi) menggunakan excavator untuk mendapatkan kedalaman embung yang maksimal 
5. Proses pengangkutan buangan tanah menggunakan dump truck

6. Setelah proses normalisasi selesai, dilanjutkan proses pemberian material kedap air geomembrane bertujuan untuk menghindari resapan air di dalam embung

7. Proses penyambungan dengan tujuan merekatkan antara sisi geomembrane yang satu dengan sisi lainnya serta pemasangan pipa pemasukan air (input)

8. Semua proses dan tahapan pemasangan geomembrane telah selesai

9. Sistem pendistribusian air melalui proses penyaringan filter sederhana menggunakan 4 tabung penyaring dan 1 tandon besar sebagai pendistribusian

\section{SIMPULAN}

Dari penelitian ini dapat disimpulkan bahwa potensi air hujan yang tertampung di embung Geomembrane pada Desa Tanggung Prigel Kecamatan Glagah adalah sebagai berikut :

1. Kebutuhan air baku pada musim kemarau pada tahun 2026 sebesar $=0,001941 \mathrm{~m}^{3} /$ detik

2. Setelah adanya embung Geomembrane keadaan air di Desa Tanggung Prigel cukup baik, dengan debit rancangan sebesar $0,003254 \mathrm{~m}^{3} /$ detik maka kebutuhan air bersih (baku) sepenuhnya bisa tercukupi

\section{DAFTAR PUSTAKA}

Abidin, Zainal, 2010, Pemanfaatan Potensi Air Hujan dengan menggunakan cistern sebagai alternatif sumber air bersih pada gedung Department Teknik Sipil FTUI (skripsi). Fakultas Teknik Universitas Indonesia

Agustapraja, $\quad$ H.R., 2019, Pengembangan Konsep Ecotourism Pada Sendang Desa Tekerharjo, Kecamatan Solokuro, Kabupaten Lamongan. Jurnal Teknika, 11(1), 1077-1082

Agustapraja, H.R., \& Kartikasari, D., 2017, Studi Evaluasi Pekerjaan Struktur Box Culvert Pada Proyek Pembangunan Jembatan Kucing Ruas SukodadiSumberwudi Kabupaten Lamongan. Ukarst, 1(1), 80-88 Alexander dan Harahab, 2009, Perencanaan Embung Tambakboyo Kabupaten Sleman DIY

Anette dan Coki, 2008, Perencanaan Detail Embung Undip sebagai Pengendalian Banjir Kanal Timur

Chao-Hsien Liaw and Yao-Lung Tsai, 2004, Optimum Storage Volume of Rooftop Rain Water Harvesting System for Domestic Use, Journal of the American Water Resources Association; Aug 2004; 40, 4; Proquest Agriculture Journals pg. 901 
Kompasiana, Memanen Air Hujan Rain Water Harvesting Sebagai Alternatif Sumber Air http://www.kompasiana.com / purwanti_asih__anna_ levi / memanen-air-hujan-rain-waterharvesting - sebagai - alternatif - sumber - air 5517a1c3a333117107b6600c)

Lancaster, Brad. Pemanenan air hujan 2006 untuk lahan kering, Vol.1.Rainsource Tekan dan 2) Air terjun, Patricia. 2006. Pemanenan air hujan untuk Penggunaan Pemandangan 2nd Ed , Pima County Cooperative. Extension

Mekanisasi.litbang.deptan.go.id,

Estimasi kebutuhan air tanaman daerah tropis

Potter, Merle C. and Wiggert D.C., Mechanics of Fluids.PretinceHall. USA

Rekayasa Hidrologi Modul
7Perhitungan - Tinggi - Hujan-
Rencana - Cara - Kurva -
Gumbel - 3.doc

Sharpe, William E. and Swistock, Bryan., 2008, Household Water Conservation, College of Agricultural Sciences, Agricultural Research and Cooperative Extension College of Agricultural Sciences, The Pennsylvania State University

Sosrodarsono, S., dan K. Takeda, 1976, Hidrologi untuk Pengairan. Jakarta PT. Pradnya Paramita

Thomas, Terry, tanpa tahun, Rainwater Harvesting: Practical Action, School of Engineering, University of Warwick, Coventry CV4 7AL, UK

WHO (2004), www.who.int.

Wordpress, 2008, Embung Kulak Secang (http://sumber dayaair. Wordpress.com/2008/04/15/ embung-kulak-secang/) diakses pada tanggal 18 Januari 2016

Worm, Janette \& Hattum, Tim van., 2006, Rainwater Harvesting For Domestic Use, Agrodok 43, Agromisa Foundation and CTA, Wageningen 